\title{
Samuel Beckett: Literatura y Traducción - Littérature et Traduction - Literature and Translation
}

\author{
Bernardo Santano Moreno, Concepción H. Álvarez y Severina Álvarez González (eds.) \\ Berna: Peter Lang, 2020.
}

0

Lucas Margarit

Universidad de Buenos Aires, Argentina

Los estudios sobre la obra de Samuel Beckett en español están teniendo una expansión cada vez mayor. Desde los primeros artículos en revistas especializadas como Primer Acto en la década de 1950 hasta los últimos libros publicados, la cantidad de homenajes y congresos académicos realizados en México, España y Argentina, las nuevas traducciones de sus textos llevadas a cabo en los dos lados del Atlántico, como las de las prosas por José Francisco Fernández en España o la trilogía de novelas por Matías Battistón en Argentina demuestran un interés cada vez mayor en el autor irlandés.

En esta oportunidad comentaremos un libro que reúne una serie de trabajos que tiene su origen en un proyecto de investigación académica radicado en España y un Congreso Internacional que tuvo lugar en la Universidad de Cáceres en el año 2018.

Este volumen reúne trabajos en tres idiomas, castellano, francés e inglés y recorre diferentes aspectos ligados a la traducción en la obra de Beckett, defendiendo "el principio de multiculturalidad el carácter multilingüe tanto de los encuentros académicos de los que surgen estos estudios como de la esencia misma de la obra de Samuel Beckett" (p.6).

La obra comienza con el capítulo de José Francisco Fernández "La recepción de Samuel Beckett en España. Consideraciones generales", el cual es un excelente estado de la cuestión con respecto a la recepción de la obra beckettiana en España desde los avatares que tuvo que atravesar durante la dictadura franquista hasta las aproximaciones más cercanas en el tiempo. En este trabajo encontramos un seguimiento de las primeras puestas de Esperando a Godot hasta las actuales y de los trabajos sobre sus obras tanto en el ámbito periodístico como en el académico donde destaca la figura pionera de Antonia Rodríguez Gago.
Entre los aspectos que focaliza su artículo, Fernández habla también de las traducciones, las interpretaciones políticas y las "malas lecturas" que ha tenido la obra de Beckett en la península.

Los siguientes dos capítulos se centran en una obra de Beckett cada uno y su repercusión y trascendencia en España. El primero de Raquel Merino-Álvarez y Olaia Andaluz-Pinedo se focaliza en Esperando a Godot realizando un detallado recorrido desde su estreno hasta las últimas representaciones y acompañan su investigación con un anexo con los expedientes de censura de la obra durante la dictadura. El segundo, de Nuria Fernández-Quesada, se centrará en Fin de partida y también propone investigar el camino que tuvo esta segunda pieza de Beckett en la crítica desde su estreno en 1958. En ambos casos nos proponen un interesante y muy bien documentado recorrido que recupera la historia de las representaciones y de la crítica de estas obras.

Siguiendo esta mirada multicultural que se propone la publicación nos acercamos al capítulo "Japón en Beckett y Beckett en Japón..." de Fernando Cid Lucas y "Aproximación a la recepción e influencia de Samuel Beckett en la literatura árabe" de Rocío Velasco de Castro. En ambos capítulos las aproximaciones son claramente novedosas en trabajos escritos en español y nos permiten acercarnos a una nueva mirada sobre estas relaciones que permanecen, por lo general, en los márgenes de los estudios académicos. Rescato de estos dos trabajos las relaciones que los investigadores proponen en un intercambio que proyecta la obra de Beckett hacia nuevos paradigmas de interpretación, ya sea con el teatro Noh japonés, como con los modos en que es leída su obra en los países árabes. En ambos casos se nos presenta un comentario sobre la traducción de la obra de Beckett en esos idiomas. 
Otro de los conjuntos de trabajos presentados en este volumen exponen cuestiones más teóricas o más amplias en relación a la obra de nuestro autor: relaciones intertextuales con la Biblia, el pesimismo y el juego, el surrealismo y la poética de Paul Éluard, la relación de la figura del clown con la metafísica, el detallado estudio de la correspondencia de la obra beckettiana con el tiempo y la lectura de Proust o el interesante "Beckett lu par Gilles Deleuze", etc.

Siguiendo el eje del congreso encontramos otros trabajos centrados en el tema de la traducción como el de Fábio de Souza Andrade donde trata el tema de su experiencia como traductor de Beckett en Brasil; el de Ignacio Infante quien reflexiona sobre el problema de la traducción en Endgame y el problema de la traducción del sistema lírico; por último Cecilia Weddell colaboró con un trabajo sobre Mexican Poetry donde trata acerca de los pormenores de esta antología y lleva a cabo un análisis de algunos ejemplos de esta labor del Beckett de los años 1950. Kim Yoojung escribe su texto sobre un tema controvertido, la "pseudo-traducción" de un texto "F-" sobre el que se pone en duda la autoría de la traducción.

Por último, nos encontramos con una completa bibliografía comentada sobre el tema del bilingüismo y la auto-traducción en manos de un investigador que conoce muy bien los conflictos teóricos sobre este tema en la obra de Beckett, Waqaz Mirza.
Como podemos ver, la variedad de aproximaciones hace de este volumen un interesante punto de apoyo para entrar en el tema de la traducción en la obra de Beckett en nuestro idioma. Asimismo, se proyecta sobre problemáticas más distantes e interesantes que nos dan otras aproximaciones tanto teóricas como con respecto a la puesta en escena en otras geografías. También es un buen material de consulta para continuar otras investigaciones a partir de las propuestas bibliográficas y los comentarios dinámicos y profundos que nos propone. Igualmente, quisiera resaltar los textos centrados en el contexto español ya que sobre esos temas circulan pocos estudios, por lo que este libro debería ser un punto de partida acerca de este tema en los estudios beckettianos en España.

Reunir esta serie de 16 trabajos, no sólo representa un gran esfuerzo por parte de los editores, sino también un desafío a la organización del libro en los temas y en la calidad que en ellos encontramos. La brevedad de este espacio y al tratarse de una reseña, me impide explayarme más en el comentario de algunos capítulos o zonas que me han parecido más fructíferos (las referencias al franquismo, la relación con Japón o el Surrealismo entre otros). Dejo al lector que su curiosidad haga un recorrido similar sobre este libro y conozca otras zonas para comenzar a reflexionar sobre la obra beckettiana. 